\title{
Cell-Free DNA Testing for Fetal Chromosomal Anomalies in clinical practice: Austrian-German-Swiss Recommendations for non-invasive prenatal tests (NIPT)
}

\section{Drei Länder - Empfehlung zum Einsatz von Nicht-invasiven pränatalen Tests (NIPT) zur Analyse der zellfreien DNA (cfDNA) im mütterlichen Blut zum Screening auf fetale Chromosomenstörungen in der klinischen Praxis}

Authors
Affiliations
Key words
chromosomal aberration
Down syndrome
genetic defects
laboratory tests
ultrasound

Bibliography DOI http://dx.doi.org/ 10.1055/s-0035-1553804 Published online: 2015 Ultraschall in Med 2015; 36: 507-510 @ Georg Thieme Verlag KG Stuttgart · New York . ISSN 0172-4614

\footnotetext{
Correspondence

Österreich: Ass. Prof. Priv. Doz. Dr. med. Maximilian Schmid, Universitätsklinik für Frauenheilkunde Wien, E-Mail: maximilian. schmid@meduniwien.ac.at, Assoz. Prof. Priv.-Doz. Dr. Philipp Klaritsch, Universitätsklinik für Frauenheilkunde und Geburtshilfe, Medizinische Universität Graz (Austria), E-Mail: philipp. klaritsch@medunigraz.at Deutschland: Prof. Dr. Bernd Eiben, MVZ Institut für Labormedizin und Klinische Genetik Rhein/Ruhr GmbH, E-Mail: eiben@eurogen.de Schweiz: Prof. Dr. med. Sevgi Tercanli, Ultraschall FreieStrasse Basel, E-Mail: sevgi. tercanli@unibas.ch
}

M. Schmid ${ }^{1}$, P. Klaritsch², W. Arzt ${ }^{3}$, T. Burkhardt ${ }^{4}$, H. C. Duba ${ }^{5}$, M. Häusler ${ }^{2}$, E. Hafner ${ }^{7}$, U. Lang ${ }^{2}$, B. Pertl ${ }^{6}$, M. Speicher ${ }^{8}$, H. Steiner ${ }^{9}$, S. Tercanli ${ }^{10}$, E. Merz ${ }^{11}$, K. S. Heling ${ }^{12}$, B. Eiben ${ }^{13}$

Affiliation addresses are listed at the end of the article.

Supported by the following professional associations:

\section{Austria:}

Austrian Society of Obstetrics and Gynecology Austrian Society of Ultrasound in Medicine Austrian Society of Pre- and Perinatal Medicine Austrian Society of Human Genetics

Schmid M., Klaritsch P., Arzt W., Duba C., Häusler M., Hafner E., Lang U., Pertl B., Speicher M., Steiner $\mathrm{H}$.

\section{Germany:}

German Society of Ultrasound in Medicine

Fetal Medicine Foundation Germany

Eiben B., Heling K.-S., Merz E.

Switzerland:

Swiss Society of Ultrasound in Medicine

Tercanli S., Burkhardt T.

\section{Recommendations - overview $\nabla$}

1. cfDNA testing should be offered only after, or in conjunction with, a qualified ultrasound and following appropriate counseling about the nature, scope and significance of the test.

2. cfDNA tests are screening tests. A high-risk cfDNA testing result should always be confirmed by an invasive diagnostic test (Chorionic villous sampling, amniocentesis), before a clinical consequence is drawn from the findings.

3. cfDNA testing can be used as secondary screening test for trisomy 21 (Down syndrome) for the reduction of invasive procedures after a high or intermediate risk result from First-trimester combined test (1 in 1,000 or > 1: 500 (FMF-D)). It should be noted that, even when cfDNA testing is used as a secondary screening, invasive diagnostic testing (Chorionic villous sampling, amniocentesis) is still the method of choice when the adjusted risk for trisomy 21 after the combined test is $>1: 10$ or the fetal nuchal translucency thickness is $>3.5 \mathrm{~mm}$ or a fetal malformation is present.

4. cfDNA tests can also be used as a primary screening method for fetal trisomy 21 in pregnant women of every age and risk group.

5. In general, it should be noted that the performance of cfDNA screening for trisomy 18 (Edwards syndrome) and trisomy 13 (Patau syndrome) is lower than that for trisomy 21.

6. Based on the available evidence the use of cfDNA tests to screen for aneuploidy of sex chromosomes and microdeletion syndroms can currently not be recommended without reservation. 


\section{Preamble}

$\nabla$

Noninvasive prenatal testing (NIPT), also referred to as cell-free DNA (cfDNA) testing, allows reliable assessment of the risks for common fetal chromosome abnormalities. The test is based on the known fact that genetic material of the mother and the fetus is present in the maternal blood (cell-free DNA, cfDNA). The genetic material of the fetus comes largely from the placenta. This material is examined using highly sophisticated testing methods (next generation sequencing, microarray analysis). By measuring the concentration and distribution of the cfDNA, a risk analysis is performed to determine whether the unborn child could be affected by a chromosome abnormality. This cfDNA analysis is subject to the Gene Technology Act in Austria, the Federal Law on Genetic Testing on Humans in Switzerland, and the Genetic Diagnosis Act in Germany. These country-specific laws regulate informed consent, physician qualifications, and analysis modalities in the genetics lab.

Depending on the particular test, this new screening method can be performed already from $9+1$ gestational weeks. Due to its excellent sensitivity and specificity, in particular as a screening test for trisomy 21 (Down syndrome), it has higher diagnostic significance than first trimester screening via the combined test (measurement of fetal nuchal translucency, determination of PAPP-A and free beta-hCG). It must be taken into consideration that the test is a screening test and is not diagnostic. Therefore, false-negative and false-positive findings are possible with the cfDNA test. Moreover, only screening for the presence of trisomy 21 (Down syndrome), trisomy 18 (Edwards syndrome) and trisomy 13 (Patau syndrome) is typically routinely performed. Some test providers offer the option to test for sex chromosome aneuploidies, triploidy, and microdeletion syndromes. However, cytogenetic diagnosis of all 46 fetal chromosomes is still only possible via invasive testing (amniocentesis, chrionic villus sampling). The use of cfDNA tests is currently often limited to secondary screening after a positive or intermediate combined test result, primarily for economic reasons. However, new data show that cfDNA tests are superior to the combined test even in primary screening for trisomy 21. The use of cfDNA tests for screening for sex chromosome aneuploidies is controversial for ethical reasons. Use for screening for microdeletion syndromes also currently cannot be recommended without restriction on the basis of the present data.

\section{Recommendations}

$\nabla$

1. cfDNA tests should only be offered after or in connection with an ultrasound scan and after the patient has been duly informed of the nature, scope, and diagnostic significance of the test.

As a rule, every pregnant woman should be informed of the option to screen for fetal structural and genetic diseases. If she decides to undergo screening for trisomy 13,18 , and 21 , she should be informed of the different methods (combined test, cfDNA test, and invasive prenatal genetic testing) as well as each method's detection rates and risks. Prenatal screening is used for early detection of structural and genetic diseases in fetuses. As early as $11+0$ gestational weeks, a number of anatomical fetal structures (e.g. head and brain, hands and feet, spinal column, heart, diaphragm, and abdominal wall) can be visualized with a detailed ultrasound examination. Various larger malformations can also be detected at this time. A recent meta-analysis shows that up to $51 \%$ of fetal malformations can be detected early via ultrasound in the first trimester [1]. Therefore, fetal size and anatomy should always be examined via ultrasound regardless of the method used to screen for genetic diseases [2].

\section{2. cfDNA tests are screening tests. Positive cfDNA test} results must always be verified by invasive testing (chorionic villus sampling, amniocentesis) before drawing clinical conclusions from findings.

The patient must be informed that a cfDNA test cannot always be successfully performed (test failure). The most common reason for this is an insufficient percentage of fetal cfDNA in the total cfDNA (fetal DNA fraction) [3, 4]. Therefore, specification of the fetal DNA fraction on the finding is a main condition for a reliable cfDNA test. This must be taken into consideration when selecting a suitable test since there are still manufacturers who do not measure or specify this value. The fetal fraction must be taken into particular consideration not only in early pregnancy but also in obese patients. The risk for an insufficient fetal fraction is higher in overweight pregnant women than in normal-weight patients [5]. If test failure occurs when using cfDNA tests for primary screening, a combined test can be used as an alternative screening method between $11+0$ and $13+6$ gestational weeks (crown rump length $45 \mathrm{~mm}-84 \mathrm{~mm}$ ). In the case of test failure in secondary screening, the test can be repeated ("redraw") or invasive prenatal genetic testing (chorionic villus sampling, amniocentesis) must be considered depending on the clinical situation. Despite significant improvements compared to previous screening methods, the sensitivity and specificity of cell-free DNA tests are not $100 \%$. Therefore, both false-negative and false-positive findings are possible. A positive result must therefore always be verified with an invasive diagnostic method (chorionic villus sampling or amniocentesis). Mosaics limited to the placenta are probably the most common cause of false-positive cfDNA test results [6]. As known from chorionic villus sampling, this can occur in up to $1 \%$ of pregnancies. The term discordant findings rather than false-positive findings should be used since the cell-free DNA test does in fact show real acquisition of cell-free DNA of a chromosome in these cases but it cannot be traced back to the fetus. A vanishing twin can also be a reason for a discordant result [7]. Therefore, in the case of known loss of a twin, use of cfDNA tests should be viewed critically and is currently not recommended. There are also very rare causes for discordant findings that have only been described in individual publications to date (mosaic finding or malignancy in the mother).

\section{3. cfDNA tests can be used as secondary screening for} trisomy 21 (Down syndrome) to reduce the number of invasive tests after positive or intermediate first trimester screening results via a combined test.

For a long time respected professional associations recommended the use of cfDNA tests only in the high-risk group [8-11]. This means primarily use as a secondary screening method after a preceding positive combined test. However, which adjusted risk value after a combined test represents an indication for cfDNA tests is currently unclear. A cut-off at a risk of $>1: 1000$ or $1: 500$ (Fetal Medicine Foundation Germany) [12, 13] was discussed. An adjusted risk of $>1: 2500$ to provide more generous indication determination was recently considered $[14,15]$. However, these values are based on theoretical considerations. Professional associations such as the German Society of Human Genetics recom- 
mend providing NIPT to every pregnant woman [16]. There are currently no published clinical studies or clear international recommendations. Therefore, a cut-off of $>1: 1000$ or $>1: 500$ (Fetal Medicine Foundation Germany) is recommended in the current consensus. With an adjusted risk based on a combined test result with an intermediate risk, the option of performing an additional cfDNA test should be discussed and documented accordingly. With this model a detection rate for trisomy 21 of $97 \%$ can theoretically be ensured at a cut-off of $>1: 1000[15,17]$.

In Switzerland the costs for cfDNA tests in the case of an adjusted risk based on the combined test of $>1: 1000$ have been covered by health insurance since July 2015. When using the test as a secondary screening method, it must be taken into consideration that invasive testing (chorionic villus sampling, amniocentesis) is still the method of choice in the case of an adjusted risk for trisomy 21 based on the combined test of $>1: 10$ or in the case of sonographic detection of a fetal nuchal translucency $>3.5 \mathrm{~mm}$ or a fetal malformation $[18,19]$. In these cases the option of prenatal genetic analysis via CGH microarray should also be discussed. In this way the common aneuploidies as well as other chromosomal aberrations can be ruled out in a timely manner. Regardless of this, counselling and more comprehensive testing at a reference center are recommended in Switzerland in case of a nuchal translucency $>95^{\text {th }}$ percentile.

The goal of cell-free DNA tests as secondary screening is primarily to reduce the number of invasive tests following a positive combined test. This is based on the fact that the combined test has a significantly higher false-positive rate of $5 \%$ or $3.42 \%$ in the case of the algorithm of the Fetal Medicine Foundation Germany for trisomy 21 and $1.6 \%$ for trisomy 13/18 [12] compared to the false-positive rate of the cfDNA test of $<0.1 \%$. Therefore, in the case of a positive combined test, the patient should be informed of the option of invasive prenatal genetic testing (chorionic villus sampling, amniocentesis) as well as cfDNA testing. However, the question of the cut-off is ultimately an individual decision and must be discussed with the patient.

4. cfDNA tests can also be used as a primary screening test for fetal trisomy 21 in pregnant women of any age and every risk group.

New studies show that the sensitivity and specificity of cell-free DNA tests are greatly superior to those of the combined test even in collectives with a primarily low or average risk and use of cfDNA tests as a primary screening method is reasonable [20, 21]. As a result of NIPT and ultrasound, detection rates of $>99 \%$ for trisomy 21 with a low false-positive rate of $<0.1 \%$ can theoretically be achieved [22]. Therefore, for example, a detailed ultrasound examination including nuchal translucency measurement starting at approx. $12+0$ gestational weeks could be combined with a cfDNA blood draw. An alternative approach suggested by the Fetal Medicine Foundation UK is to perform the blood draw as early as $10+0$ gestational weeks. The crown rump length should be at least $32 \mathrm{~mm}$. When the result of the cell-free DNA test is available approximately 2 weeks later, the results are discussed and first-trimester screening via ultrasound and measurement of the fetal nuchal translucency is performed. In the case of sonographic detection of a nuchal translucency $>3.5 \mathrm{~mm}$ or a fetal malformation, invasive prenatal genetic testing including microarray analysis is recommended regardless of the cfDNA test result $[18,19]$.

\section{In general, it must be taken into consideration that the} performance of cfDNA screening for trisomy 18 (Edwards syndrome) and trisomy 13 (Patau syndrome) is less than the performance of cfDNA screening for trisomy 21.

A summary of the major studies published to date for singleton pregnancies regardless of the method yields the following data [22]:

- Trisomy 21 - detection rate $99.2 \%$; false-positive rate $0.09 \%$

- Trisomy 18 - detection rate $96.3 \%$; false-positive rate $0.13 \%$

- Trisomy 13 - detection rate $91.0 \%$; false-positive rate $0.13 \%$

In particular the definite limitation of the test quality for trisomy 13 should be noted here. In addition to technical factors ("GC bias" in MPSS), the reason for this seems to be the frequent presence of mosaics in the placenta for trisomies 13 and 18 [23]. In the case of cfDNA test results with a high risk for these two aneuploidies, amniocentesis is therefore the method of choice for further testing. It should also be noted that trisomies 18 and 13 can be identified early in most cases by ultrasound examination.

\section{The use of cfDNA tests for screening for sex chromo-} some aneuploidies and for microdeletion syndromes currently cannot be recommended without restriction on the basis of the present data.

Even though commercial providers of cell-free DNA tests are attempting to test for an ever increasing number of diseases, testing for all genetic diseases will not be possible in the near future. It must be taken into consideration that new indications/clinical pictures significantly increase the cumulative false-positive rate of the tests. This negates a significant advantage over the combined test. This is particularly true for microdeletion syndromes. Moreover, there is currently barely reliable clinical evidence for this indication. If available, data regarding test quality are derived from an extremely small number of subjects, many of whom were examined exclusively in vitro [24]. Screening for microdeletion syndromes via cfDNA tests is also problematic because the usually low incidence of these syndromes results in false-positive cfDNA test results being generated and a certain microdeletion syndrome cannot really be ruled out via a cfDNA test with a low sensitivity. Moreover, testing is only performed for a limited number of microdeletion syndromes. Thus, even after a negative test, there is no significant change in the a priori risk for microdeletion syndromes. If screening for individual microdeletion syndromes via cfDNA analysis is desired, this should be limited to clinically relevant microdeletion syndromes with a significant prevalence and a defined phenotype. An example of this is screening for microdeletion 22q11 (DiGeorge syndrome) [25]. Finally it should be noted that although there are already promising experiments regarding the detection of monogenetic diseases via cfDNA tests, such applications must currently still be viewed as experimental and should only be recommended in clinical studies [26].

The use of cell-free DNA tests for screening for sex chromosome abnormalities is controversial. A current meta-analysis shows that the detection rate for monosomy X (Turner syndrome) and other sex chromosome abnormalities (e.g. XXX, Klinefelter syndrome) is $90.3-93.0 \%$ with false-positive rates of $0.14 \%$ to $0.23 \%$ [22]. The test quality is thus significantly lower than that for trisomy 21. It must also be noted that none of the evaluated studies can provide reliable data regarding detection rates since there was usually no cytogenetic evaluation of children with a phenotypic abnormality. Moreover, counseling in the case of a 
positive test is difficult: The clinical phenotype in sex chromosome abnormalities is very variable and many of those affected only suffer from mild physical or mental developmental disorders if at all. Many experts therefore reject screening for sex chromosome aneuploidies. In any case it is undisputed that every pregnant woman must be thoroughly counseled prior to screening for sex chromosome aneuploidies.

\section{Affiliations}

${ }^{1}$ Abteilung für Geburtshilfe und feto-maternale Medizin, Universitätsklinik für Frauenheilkunde Wien (Österreich)

2 Universitätsklinik für Frauenheilkunde und Geburtshilfe, Medizinische Universität Graz (Österreich)

3 Abteilung für Pränatalmedizin, Landesfrauen- und Kinderklinik Linz (Österreich)

${ }^{4}$ Klinik für Geburtshilfe, Universitäts-Spital Zürich (Schweiz)

${ }^{5}$ Zentrum Medizinische Genetik, Landes-Frauen- und Kinderklinik Linz (Österreich)

6 Pränatalzentrum, Privatklinik Graz-Ragnitz (Österreich)

${ }^{7}$ Geburtshilflich-Gynäkologische Abteilung, Sozialmedizinisches Zentrum Ost - Donauspital, Wien (Österreich)

8 Institut für Humangenetik, Universität Graz (Österreich)

9 Praxis für Pränatalmedizin, Praxis für Pränatalmedizin, Salzburg (Österreich)

10 Ultraschall Freie-Strasse, Basel (Schweiz)

11 Zentrum für Ultraschall und Pränatalmedizin; Frankfurt (Deutschland)

12 Praxis Friedrichstrasse für Pränataldiagnostik, Berlin (Deutschland)

13 Institut für Labormedizin und Klinische Genetik Rhein/ Ruhr, amedes Gruppe, Essen (Deutschland)

\section{References}

1 Rossi AC, Prefumo F. Accuracy of ultrasonography at 11-14 weeks of gestation for detection of fetal structural anomalies: a systematic review. Obstet Gynecol 2013; 122: 1160-1167

2 Salomon LJ, Alfirevic Z, Audibert F et al. ISUOG consensus statement on the impact of non-invasive prenatal testing (NIPT) on prenatal ultrasound practice. Z Geburtshilfe Neonatol 2014; 218: 242-243

3 Willems PJ, Dierickx H, Vandenakker E et al. The first 3,000 Non-Invasive Prenatal Tests (NIPT) with the Harmony test in Belgium and the Netherlands. Facts Views Vis Obgyn 2014; 6: 7-12

4 Eiben B, Krapp M, Borth $H$ et al. Single-Nucleotide-Polymorphismbased Analysis of Cell-Free fetal DNA in 3000 cases from Germany and Austria. Ultrasound International Open 2015; 01: E8-E11

5 Wang E, Batey A, Struble C et al. Gestational age and maternal weight effects on fetal cell-free DNA in maternal plasma. Prenat Diagn 2013; 33: $662-666$

6 Mao J, Wang T, Wang BJ et al. Confined placental origin of the circulating cell free fetal DNA revealed by a discordant non-invasive prenatal test result in a trisomy 18 pregnancy. Clin Chim Acta 2014; 433: 190 193

7 Curnow KJ, Wilkins-Haug L, Ryan A et al. Detection of triploid, molar, and vanishing twin pregnancies by a single-nucleotide polymorphism-based noninvasive prenatal test. Am J Obstet Gynecol 2015; 212: 79
8 Gregg AR, Gross SJ, Best RG et al. ACMG statement on noninvasive prenatal screening for fetal aneuploidy. Genet Med 2013; 15: 395-398

9 American College of Obstetricians and Gynecologists Committee on Genetics. Committee Opinion No. 545: Noninvasive prenatal testing for fetal aneuploidy. Obstet Gynecol 2012; 120: 1532 -1534

10 Devers PL, Cronister A, Ormond KE et al. Noninvasive prenatal testing/ noninvasive prenatal diagnosis: the position of the National Society of Genetic Counselors. J Genet Couns 2013; 22: 291 - 295

11 Benn P, Borell A, Chiu R et al. Position statement from the Aneuploidy Screening Committee on behalf of the Board of the International Society for Prenatal Diagnosis. Prenat Diagn 2013; 33: 622 - 629

12 Merz E, Thode C, Eiben B et al. Individualized correction for maternal weight in calculating the risk of chromosomal abnormalities with first-trimester screening data. Ultraschall in Med 2011; 32: 33-39

13 Eiben B, Thode C, Merz E. Nichtinvasive Pränataldiagnostik-Serumtestsyteme zur Erfassung von Chromosomenanomalien. Gynäkologie + Geburtshilfe 2013; 18: 2-4

14 Kagan KO, Wright $D$, Nicolaides $K H$. First-trimester contingent screening for trisomies 21,18 and 13 by fetal nuchal translucency and ductus venosus flow and maternal blood cell-free DNA testing. Ultrasound Obstet Gynecol 2015; 45: $42-47$

15 Nicolaides KH, Syngelaki A, Poon LC et al. First-trimester contingent creening for trisomies 21,18 and 13 by biomarkers and maternal blood cell-free DNA testing. Fetal Diagn Ther 2014; 35: 185-192

16 Stellungnahme der Deutschen Gesellschaft für Humangenetik (GfH) zur Analyse fetaler DNA aus dem mütterlichen Blut. http://www. gfhev.de/de/leitlinien/LL_und_Stellungnahmen/ 2012_11_12_GfH_Stellungnahme_Analyse_fetale_DNA.pdf

17 Kagan KO, Hoopmann M, Hammer R et al. Screening auf Chromosomenstörungen mittels Ersttrimester-Screening und non-invasive prenatal Testing. Ultraschall in Med 2015; 36: 40-46

18 Gil MM, Quezada MS, Bregant B et al. Implementation of maternal blood cell-free DNA testing in early screening for aneuploidies. Ultrasound Obstet Gynecol 2013; 42: 34-40

19 Lund IC, Christensen R, Petersen OB et al. Chromosomal microarray in fetuses with increased nuchal translucency. Ultrasound Obstet Gynecol 2015; 45: 95-100

20 Bianchi DW, Parker RL, Wentworth J et al. DNA sequencing versus standard prenatal aneuploidy screening. N Engl J Med 2014; 370: $799-808$

21 Norton ME, Jacobsson B, Swamy GK et al. Cell-free DNA Analysis for Noninvasive Examination of Trisomy. N Engl J Med 2015

22 Gil MM, Quezada MS, Revello R et al. Analysis of cell-free DNA in maternal blood in screening for fetal aneuploidies: updated meta-analysis. Ultrasound Obstet Gynecol 2015

23 Kalousek DK, Barrett IJ, McGillivray BC. Placental mosaicism and intrauterine vival of trisomies 13 and 18. Am J Hum Genet 1989; 44: 338 343

24 Wapner RJ, Babiarz JE, Levy B et al. Expanding the scope of noninvasive prenatal testing:detection of fetal microdeletion syndromes. Am J Obstet Gynecol 2014, pii:S0002-9378(14)02374-6

25 Eiben B, Glaubitz R, Kagan KO. Nichtinvasive Pränataldiagnostik. ETS und NGS-basierte Tests. Medgen Springer-Verlag; 2014

26 Chitty LS, Khalil A, Barrett AN et al. Safe, accurate, prenatal diagnosis of thanatophoric dysplasia using ultrasound and free fetal DNA. Prenat Diagn 2013; 33: 416-423 